\title{
CORROSION INHIBITION PROPERTIES OF TELFAIRA OCCIDENTALIS LEAF EXTRACT ON ALUMINIUM IN 1.5M HCL MEDIUM
}

Dawodu F. A. ${ }^{1}$ and Sodiya E. F. ${ }^{2 *}$

1,2, *Chemistry Department, Faculty of Science, University of Ibadan

*Corresponding Author: -

E -mail: sodiyaezekiel@gmail.com

\begin{abstract}
: -
Corrosion inhibition of aluminium by leaf extract Telfaira occidentalis in $1.5 \mathrm{M} \mathrm{HCl}$ was investigated using the gasometric technique at $28^{\circ} \mathrm{C}$. Results obtained showed that the extract displayed high inhibition efficiency against corrosion of aluminium in $1.5 \mathrm{M} \mathrm{HCl}$ solution. The extract displayed nearly the inhibition efficiencies at concentration range $10-50 \%$ dilution of the extract. The corrosion inhibition mechanism followed Langmuir adsorption isotherm at the studied temperature. This suggests the extract constituent chemisorbed on the aluminium surface forming a protective film minimising direct contact with the corrodent.
\end{abstract}

Keywords: Telfaira occidentalis, Aluminium, induction time, corrosion inhibition, Langmuir adsorption isotherm. 


\section{INTRODUCTION}

Through photosynthesis plants harvest solar energy as stored primary metabolites which serve as food for man and animal. Plants also produce secondary metabolites that they used as defence weapon against foreign attack and for adapting during adverse climatic conditions. Vaishnay and Demain 2011, Rogerio et al 2010. The secondary metabolites are known as phytochemicals. There are many ethnopharmacological applications of phytochemicals for curing ailments.Chengaiah et al 2013. The use of phytochemicals usually obtained in form of extracts or concoctions as therapeutic agents dates back to many human civilisations to the present time. Saxena et al 2013. The phytochemicals also have applications $\mathrm{n}$ the dye and leather industries. Gohari et al 2013, Falcao et al 2009. In recent times, plants phytochemicals are also finding applications as corrosion inhibitorsVaishnay and Demain et al 2011.

Synthetic organic such as Pyrazolo[3,4-b] pyridine. Rogerio et al 2010. Schiff bases of ethylenediamine. Chengaiah et al 2013, Quinolines Saxena et al 2013, Pyridoxal and Pyridoxol hydrochlorides Gohari et al 2013, etc, have been investigated as corrosion inhibitors. There compounds are contain heteroatom by which they chemisorbed on metal surface they constituting a protective coating film that prevents or minimise direct the corrodents Falcao et al 2009, Agrawal et al 2004. However, there have been concerns for both human health and local ecosystem about the toxicity of these synthetic organic compounds. Hence, there are extensive investigations on green corrosion inhibitors in recent times. Plants phytochemicals are bioactive heterocyclic organic compounds which range from alkaloids, tannins, saponins, steroids, terpenoids, flavonoids, etc. In addition to being biodegradable and less toxic than synthetic corrosion inhibitors, presence of heteroatoms and conjugated bonds in plant phytochemicals impacts on them ability to function as corrosion inhibitors, and a sustainable and inexpensive green corrosion inhibitors.

Although aluminium has high electronegative potential $(-1.67 \mathrm{~V})$, it has high resistant to general corrosion due to the formation of a protective surface oxide film. Ebenso et al 2010. This resistance is due to the inert and protective character of the Aluminium oxide film which forms on the metal surface. The durability of Aluminium enables its use in many applications and in doing so it may come into contact with aggressive environments. However corrodes rapidly in aggressive corrosion media such $\mathrm{HCl}$ solution.Telfaira occidentalis is a tropical vine that grows in West Africa. The leaves and the young shoots are the mainly eaten as vegetables Burkill 1985,Nyananyo 2006 2013. Leaves of Telfaira occidentalis have been shown to rich in proteins, flavonoid, saponins, phenolic etc Falcao et al 2009. These phytochemicals indicates that Telfaira occidentalis leaf extracts have potentials as green corrosion inhibitor. However, there is scanty report on corrosion inhibition properties of extracts from Telfaira occidentalis. It is therefore of interest to investigated corrosion inhibition properties of methanolic extracts of the leaf of Telfaira occidentalis on aluminium.

\section{Materials and method}

A $1 \mathrm{~mm}$ aluminium sheet was cut into coupons of $24 \times 14 \mathrm{~mm}$. The coupons were degreased in absolute ethanol and washed in acetone and then dried in a desiccator. James et al 2011. Elemental composition of the aluminium sheet as analysed using Metal Spectrometer Analyser of Model ARL Quanbo Desk OTD 226 (Optical emission) is shown in Table 1.

Table 1: Elemental composition of the Aluminium coupon

\begin{tabular}{|l|l|l|l|l|l|l|l|l|l|l|l|}
\hline Element & $\mathrm{Al}$ & $\mathrm{Si}$ & $\mathrm{Fe}$ & $\mathrm{Mg}$ & $\mathrm{Zn}$ & $\mathrm{Ni}$ & $\mathrm{Ti}$ & $\mathrm{Cd}$ & $\mathrm{Cu}$ & $\mathrm{B}$ & $\mathrm{Mn}$ \\
\hline wt \% & 99.10 & 0.176 & 0.60 & 0.0021 & $\begin{array}{c}< \\
0.001\end{array}$ & 0.0027 & 0.025 & 0.0015 & 0.093 & 0.0055 & 0.015 \\
\hline
\end{tabular}

Leaves of Telfaira accidentails were air dried and ground into powder. The powder $(100 \mathrm{~g})$ was weighed into $1 \mathrm{~L}$ of $90 \%$ methanol in a $2 \mathrm{~L}$ volumetric flask. The flask was properly corked and left to stand for 48 hours with occasional shaking. The resultant mixture was filtered and the methanol was evaporated to obtain dark brown thick slurry at $65^{\circ} \mathrm{C}$ using rotatory evaporator. The $50 \mathrm{ml}$ crude extract was made up to $1 \mathrm{~L}$ stock solution with $1.5 \mathrm{M}$ Hydrochloric Acid solution. $50 \mathrm{ml}$ of stock solutions diluted with $450 \mathrm{ml}$ of $1.5 \mathrm{M}$ Hydrochloric acid solution (10\% solution), subsequent dilutions were made with $1.5 \mathrm{M} \mathrm{HCl}$ solution thus $100 \mathrm{ml}$ of stock solution diluted with $400 \mathrm{ml}(20 \%$ solution), $150 \mathrm{ml}$ diluted with $350 \mathrm{ml}$ (30\% solution), $200 \mathrm{ml}$ diluted with $300 \mathrm{ml}$ (40\% solution) and $250 \mathrm{ml}$ diluted with $250 \mathrm{ml}$ (50\% solution). All reagents were analar grade (BDH) and distilled water was used for the preparation of all solutions. The leave extraction Yield of Telfaira occidentalis was $4.67 \%$, this is comparable with the $4.2 \%$ Extract Yield obtained by Safia et al; 2013 in the methanolic extraction of Raphanus sativus Schematic diagram of the gasometric (gas-volumetric) technique is shown in figure 1. Detail procedure of gasometric determination of corrosion rates have been described elsewhere. Ehteram and Al Moubaraki 2008. 60ml of the corrosion medium (hydrochloric acid solution only as control) was placed in a Mylius cell. Degreased and weighed aluminium coupon was introduced into the corrodent. Volume of hydrogen gas evolved was collected and measured with the aid of a calibrated tube by downward displacement of water. The readings of $\mathrm{H}_{2}$ evolved were taken at intervals1minutes for minimum of 10 minutes. This procedure was repeated for the corrodent containing varied amount of the Telfaira occidentails extract. At the end of each gasometric experiment, the aluminium alloy specimen was removed from the corrodent solution, washed thoroughly with distilled water followed by acetone and dried in air and weighed.

Madukwe et al 2013. 


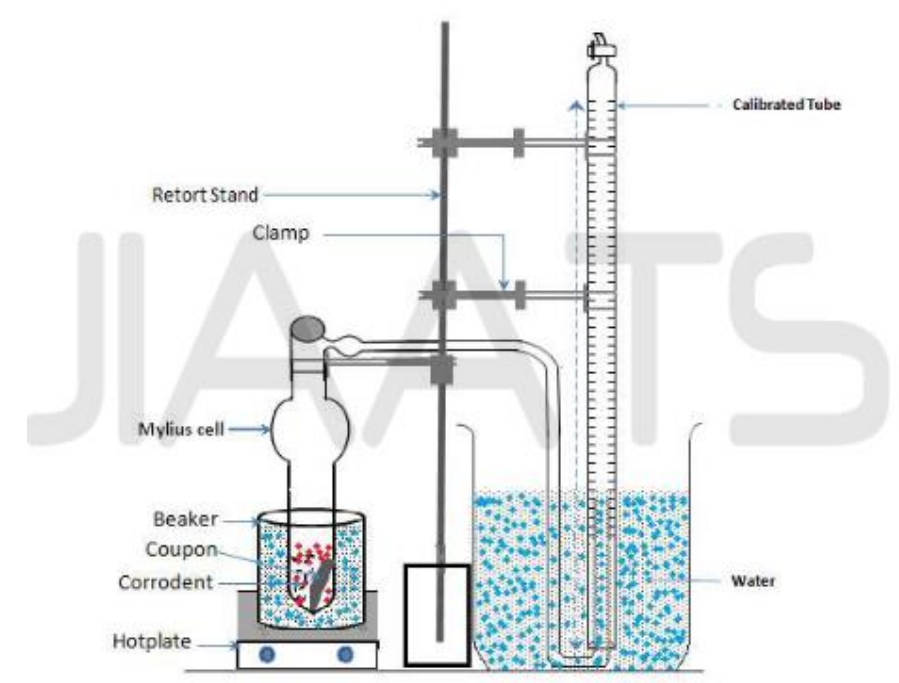

Fig.1 Schematic diagram of the system for the gasometric measurement

The basic data is the volume of hydrogen gas evolved as a function of time. Ehteram and Moubaraki, 2008 . The volume of hydrogen evolved is stoichiometrically proportional to the mass loss in the coupon.

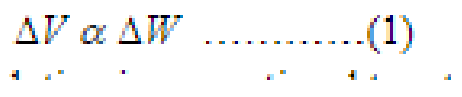

Rate of hydrogen evolution is proportional to rate of mass loss.

$$
\begin{aligned}
& \frac{\partial \Delta V}{\partial t} \alpha \frac{\partial \Delta W}{\partial t} \ldots \ldots . .(2) \\
& \text { Hence, Corrosion rate }=\frac{\partial \Delta \ddot{W}}{\partial t}=\frac{\partial \Delta V}{\partial t}
\end{aligned}
$$

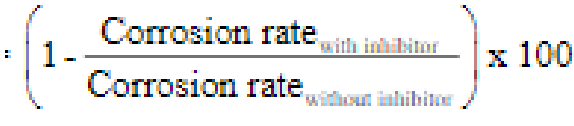
is given by:

The surface coverage $\theta$ of the inhibitor on the aluminium coupon are calculated from the corrosion rate

$$
\theta=\frac{I \cdot E \%}{100}
$$

\section{Results and discussion}

Hydrogen gas evolution from the aluminium sheet in $1.5 \mathrm{M} \mathrm{HCl}$ solution with different concentrations of the inhibitor and without the inhibitor $(0 \%)$ is presented in Figure 2. For both inhibitor containing and inhibitor free corrodent, there is about 15 minute induction time before hydrogen evolution. This induction time may be attributed to time taken for the corrodent to attacked and remove the protective oxide film on the aluminium sheet coupons. Hence, the readings after 15 minutes represent start of corrosion of the aluminium coupons. After the 15 minutes induction time hydrogen gas evolution increases rapidly from the coupon in the uninhibited corrodent solution. But hydrogen evolutions from the coupons in the inhibited corrodent solutions are very much lowered. The volume of hydrogen gas evolved with time is modelled with four degree polynomials. The expressions for the corrosion rates were obtained by the respective differentials of the hydrogen gas evolved with time. The corrosion rates of the Aluminium sheet coupons in the containing corrodent containing varied concentrations of the inhibitor are shown in Figure 3. The volume of hydrogen evolved is lower in the corrodent containing the inhibitor. This clearly shows that the inhibitor lowered corrosion rate. The corrosion rate decreased very drastically in the presence of the inhibitor. The corrosion rate of the Aluminium coupon increases rapidly with time in the uninhibited corrodent (control). While those in the inhibited corrodent lowered and increase very slowly with time. The extract showed high corrosion inhibition efficiency even at the lowest concentration used in this study. 


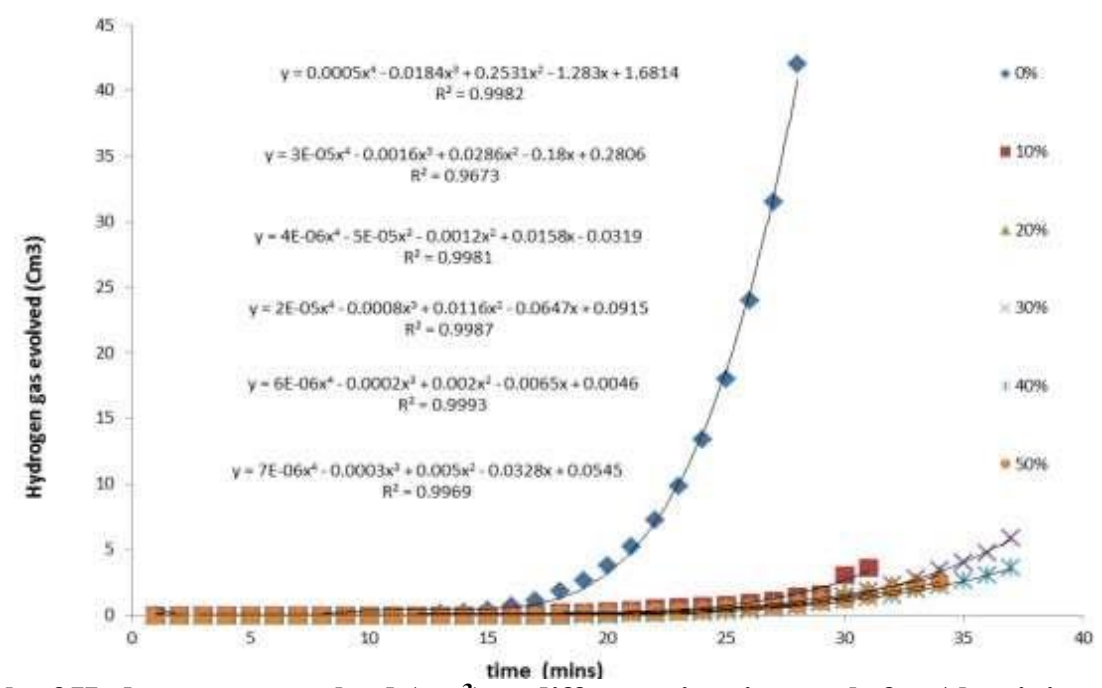

Fig 2: Graph of Hydrogen gas evolved $\left(\mathrm{cm}^{3}\right)$ at different time intervals for Aluminium corrosion in Telfaira occidentalis extracts in $1.5 \mathrm{M} \mathrm{HCl}$ at $28^{\circ} \mathrm{C}$

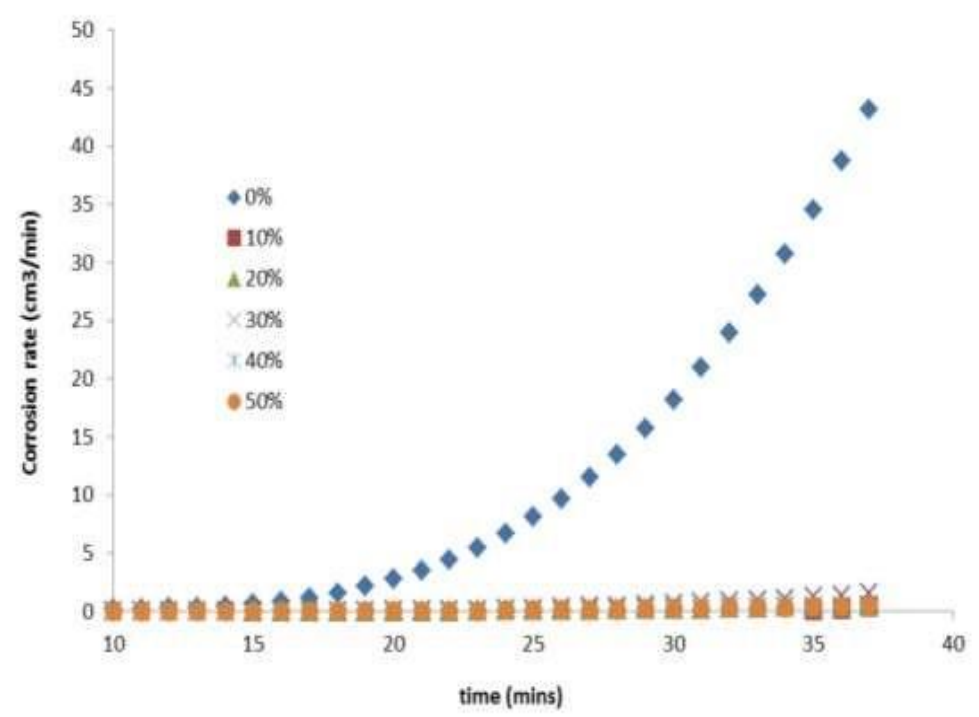

Fig. 3: Graph of Corrosion rate of Aluminium ( $\left.\mathrm{cm}^{3} / \mathrm{minute}\right)$ against time (minutes) with and without inhibitor (Telfaira occidentalis extracts) in $1.5 \mathrm{M} \mathrm{HCl}$ at $28^{\circ} \mathrm{C}$

Inhibition efficiency as a function of the concentration of the extract depicts a peak at $30 \%$ concentration (Fig. 4). This suggests the formation of full protective barrier film of inhibitor molecules on the Aluminium surface.

In Figure 5, Inhibition efficiency as a function of time shows initial passivation due to expected oxide film formed on the metal in an acidic medium. Attack of acid on the metals made the way for manifestations of extract performance. It was more evident on metals in $10 \%$ extract where the Inhibition efficiency was at least, the attack was mild on others in various extract concentration especially $30 \%$ and $40 \%$ extract concentrations 


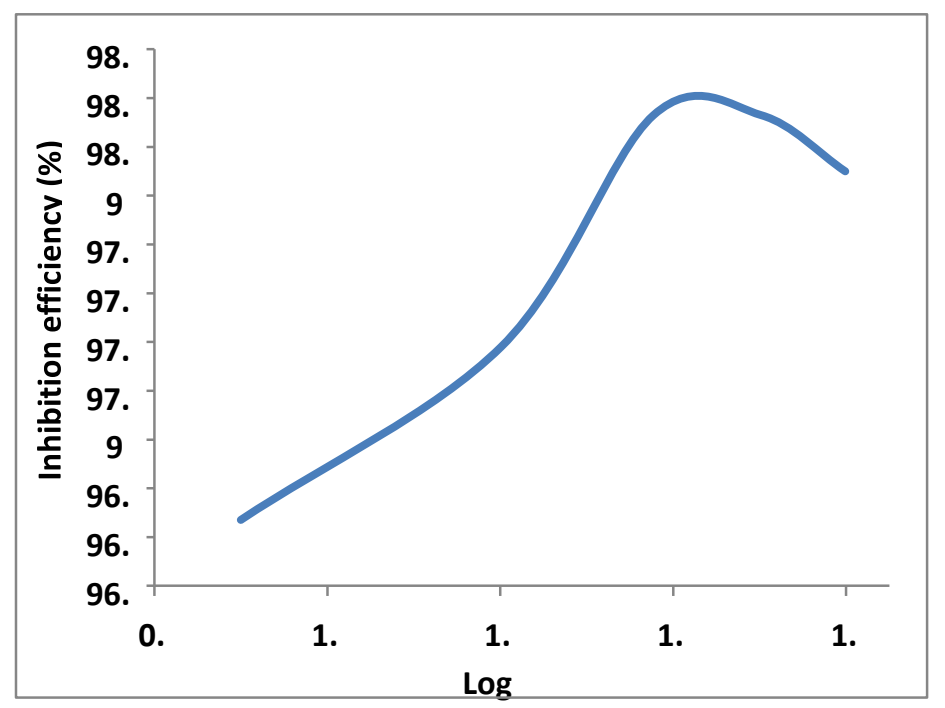

Fig. 4: Relationship between inhibition efficiency and concentration of the extract

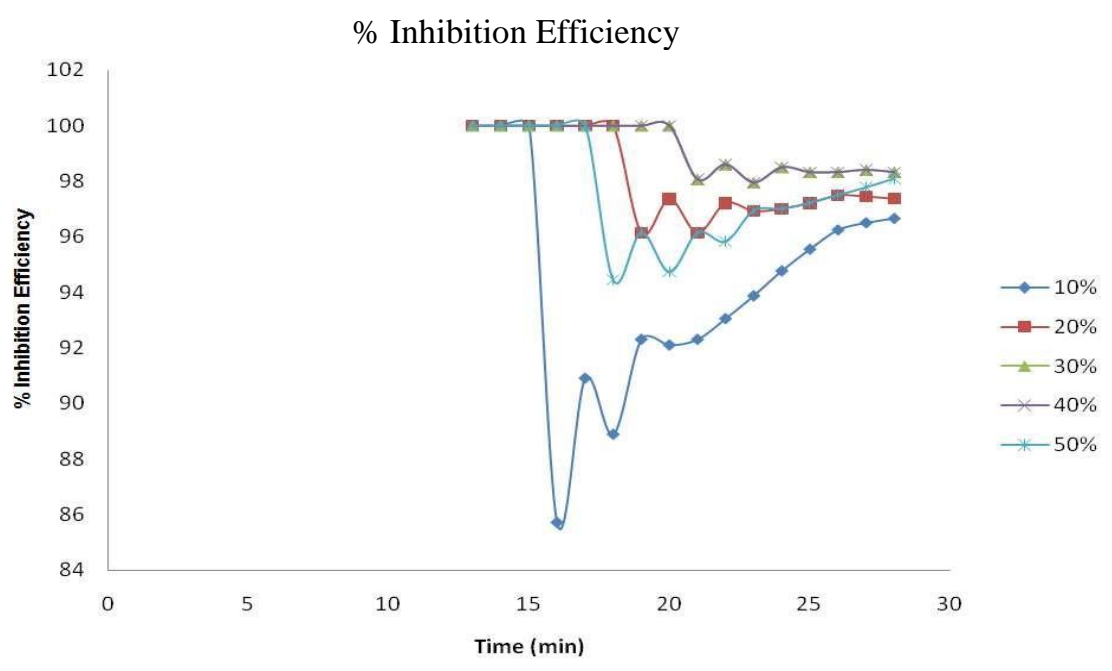

Figure 5; Graph of Inhibition.Efficiency (\%) with Time (minutes) for Aluminium corrosion in Telfaira occidentalis extracts in the presence of $1.5 \mathrm{MHCl}$ at $28^{\circ} \mathrm{C}$

\section{Kinetic Relationship for Corrosion Reactions}

The concentration dependence of Corrosion rate can be expressed as indicated below, Mathur et al 1982.

$$
\begin{aligned}
& \mathrm{r}=\mathrm{KC}^{\mathrm{B}} \\
& \log \mathrm{r}=\log \mathrm{k}+\mathrm{B} \log \mathrm{C} \\
& \log _{10} r=B \log _{10} C_{\text {extract }}+\operatorname{logk}, \quad y=-0.197 x-8.998
\end{aligned}
$$

Where: $\log r(\mathrm{~mol} / \mathrm{min})=\log$ of corrosion rate

Intercept $=\operatorname{logk}, \mathrm{k}=$ Specific reaction rate constant, $\mathrm{k}=1.00461579 \mathrm{E} 09 \mathrm{~mol} \mathrm{~min}^{-1}$

$\mathrm{B}=$ Reaction constant (the negative value infer decreasing slope due to the inhibition effect of the extract on the metal) $=$ slope $=-0.197 \mathrm{~mol}^{-1}$

$\mathrm{C}=$ Volume concentration of extracts $(\mathrm{mol})$

Corrosion rates can therefore be related to extract concentration by conversion of volume of hydrogen gas evolved in the presence of inhibitor from units of $\mathrm{ml}\left(\mathrm{cm}^{3}\right)$ to mol assuming hydrogen evolution took place at $1.01325 \times 10^{-5} \mathrm{~Pa} \mathrm{Ehteram}$ and Al Moubaraki 2008. In the same vein, a factor of 0.018700307 was employed in converting. Volume of extracts was converted from $\mathrm{ml}\left(\mathrm{cm}^{3}\right)$ to mol using the factor has been employed in different studies Ajayi et al., 2011; Mathur et al., 1982). . From the graph of relationship between $\log \mathrm{r}$ and $\log \mathrm{c}$ which gave linear expression from where $\mathrm{k}$ and $\mathrm{B}$ were obtained.

This equation and the previous graph completely depicts the difference between uninhibited and inhibited solutions as the negativity of value obtained in this study compared to that of Ehteram and Al Moubaraki 2008 when no inhibitor was used.

\section{Half-life of the Zinc in the extract}

In Figure 6, it was observed that the slope decreases with decrease in reaction rate due to increase in concentration of extract. The larger the magnitude of the intercept, the greater the value of log $\mathrm{k}$ which is solution or reference level of log 
$r$ at extrapolated zero concentration level of a particular extract. A higher intercept represent a higher starting rate of the reaction in a particular extract. Intercept $=-8.998$

Consequently Half Life $\left(t_{1 / 2}\right)$ of the metal in the corrosive media in the presence of the extract can be determined by the formula: $\mathrm{t}_{1 / 2}=\ln 2 / \mathrm{k}$, where $\ln 2=0.69314718, \mathrm{t}_{1 / 2}=$

$0.696546601 \times 10^{9}$ minutes

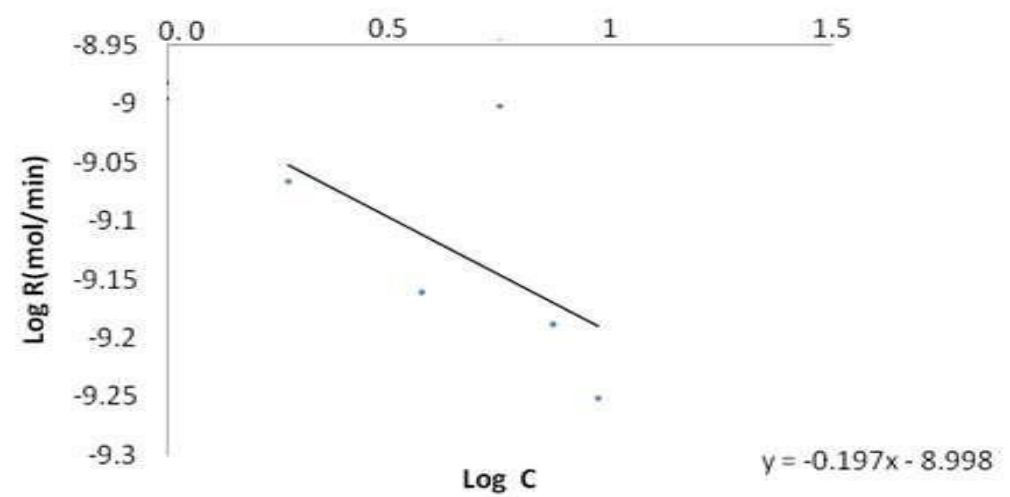

Fig. 6 Graph of Corrosion $\log \mathbf{r}(\mathrm{mol} / \mathrm{min})$ against $\log$ of various Telfaira occidentalis leave extract concentration $\mathrm{C}$ (mole) at $30^{\text {th }}$ minute for Aluminium inhibition in the presence of $1.5 \mathrm{MHCl}$ at $28^{\circ} \mathrm{C}$

\section{Adsorption studies}

Mechanism of corrosion inhibition of the extract may be due to direct interaction of the constituent of the extract with corrodent thereby lowering its effective concentration or by absorbing on the surface of the Aluminium sheet acting as a protective barrier against corrodent attack.

The surface coverage of the inhibitors molecules in the extract on the Aluminium surface agrees with Langmuir adsorption isotherm (Fig. 7). This implies that the film acts as a barrier to acid attack on the Aluminium surface.

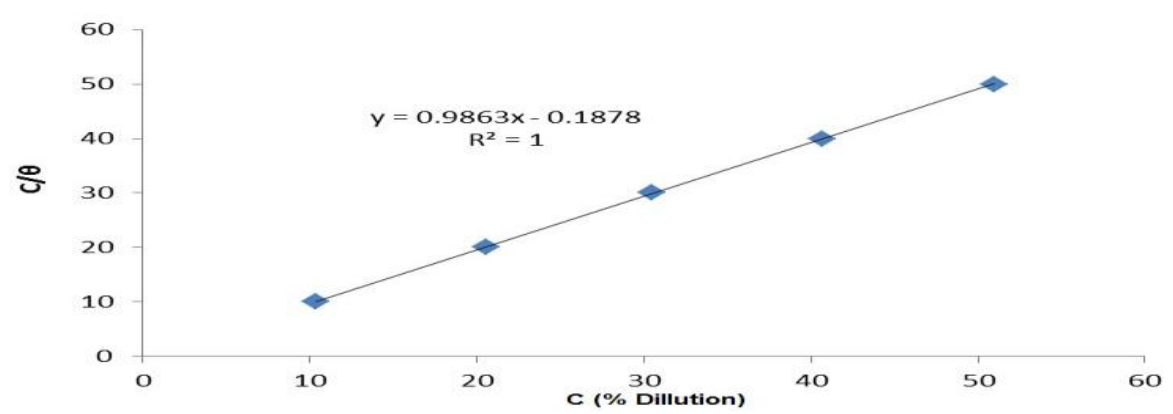

Fig 7: Langmuir adsorption isotherm plot of the extract surface coverage on the Aluminium surface

\section{Langmuir Adsorption Isotherm}

This is the most extensively utilised mechanism identical to physical adsorption (physisorption). It is assumed to be of monolayer characteristics by the adsorbate for zero or one adsorbed molecule per site $0<\theta<1$, with all sites having thesame adsorption energy and no interaction between adsorbed species or adsorption sites. It is represented by the equation:

$$
\begin{aligned}
& \varnothing=\mathrm{kC} /[1+\mathrm{kC}] \\
& \frac{\emptyset}{(\varnothing-1)}=\mathrm{kC}
\end{aligned}
$$

(6) capital $\mathrm{k}$ must be changed to small $\mathrm{k}$ in this these equations

Dividing both sides $\mathrm{K} \varnothing$ and then rearrange, we then have

Where $\varnothing=$ Surface coverage

$$
\frac{\mathrm{C}}{\varnothing}=\frac{1}{\mathrm{k}}+\mathrm{C}
$$

$\mathrm{C}=$ Concentration 2006.

$\mathrm{k}=$ characteristics constant related to adsorption intensity or degree of favourability of adsorption Lebrini et al

Graph of C/Ø (x-axis) against $\mathrm{C}$ (y-axis), was discovered to have a slope of 1 and intercept 1/k, from where $\mathrm{k}$ can be simply deduced. Taking $\log$ of both sides $\log (\mathrm{C} / \theta)=\log \mathrm{C}-\operatorname{logk}$ Sheatty et al 2006.

Graph of $\log (\mathrm{C} / \theta)$ against $\log \mathrm{C}$ give slope to be equal to 1 and intercept $-\operatorname{logK}$. On the other hand $\log \theta / 1-\theta=\log +\mathrm{ylog}$ C Atkins 1994.

Graph of $\log (\mathrm{C} / \theta)$ against $\log \mathrm{C}$ will give intercept $\log \mathrm{k}$ and slope $\mathrm{y}$ The equilibrium constant of adsorption $\mathrm{k}_{\mathrm{ads}}=\mathrm{k}^{1 / \mathrm{y}}$. where $1 / \mathrm{y}$ is the number of the surface active sites occupied by one inhibitor molecule and $\mathrm{C}$ is the bulk concentration of 
the inhibitor. Values of 1/y less than unity imply the formation of multilayer of the inhibitor on the surface of the metal. However, values of $1 / y$ greater than unity indicate that a given inhibitor molecule will occupy more than one active site. For equation $\mathrm{y}=0.9863 \mathrm{x}-0.01878$. Linear graph of Concentration $\mathrm{C}$ against $\mathrm{C} / \theta$, where $\theta$ is the surface coverage of adsorbed material from extract on metal surface. It shows the favourabilty of adsorption to Langmuir adsorption isotherm. Coefficient of determination $\mathrm{R}^{2}=1$ Correlation Coefficient $\mathrm{R}=1.1 / \mathrm{k}=0.1878$, Therefore characteristic constant $\mathrm{k}=5.32481$.

\section{Gibbs free energy}

Adsorption process is ordinarily known to have occurred when free energy value is negative. Therefore by employing the Gibbs Free energy absorption of the extract unto the metal can be calculated Yang et al., 2009).

$$
\Delta G \quad=-R T \int_{0}^{a} k \frac{d a}{a}
$$

The above Equation can be represented as

$$
\Delta \mathrm{G}=-\mathrm{kRT}
$$

Where: $\Delta \mathrm{G}=$ Free Energy change

$\mathrm{k}=$ Adsorption characteristics constant or degree of adsorption favourability

$\mathrm{R}=\mathrm{Gas}$ constant

$\mathrm{T}=$ Temperature

From Fig: 7, The Gibbs free Energy for this inhibitive reaction can evaluated $\Delta \mathrm{G}=-\mathrm{KRT} \Delta \mathrm{G}=-$

$5.32481 \times 8.314 \mathrm{JK}^{-1} \mathrm{~mol}^{-1} \times 301 \mathrm{~K}$, the negative value of $\Delta \mathrm{G}\left(-13,319.00 \mathrm{Jmol}^{-1}\right.$.) It is an indication of spontaneous physical adsorption.

\section{Morphological Analysis}

It could be observed that the grains in the internal strcuture in Plate 2.0 were highly attacked by the $1.5 \mathrm{M} \mathrm{HCl}$ in the absence of leave extract compared with the control in Plate 1.0 not immersed in acid or extract. In that Plate 2.0 there were much depletion of $\alpha$-Aluminium phase into the corrodent due to corrosive effect of the medium on the metal. This however had less effect on Al-Si and Al-Fe phases present in the sample in Plate 2, they therefore remained prominent in the structure as much of the major phase $\alpha$-Al got dissolved in to the solution In Plate 3.0, the structure of Aluminum sample immersed in leave extract indicated that the internal structure was protected, because less of $\alpha$-Al phase dissolved into the solution containing the Telfaira occidentalis extract in acidic medium due to inhibitory effect of phytoconsitutuents in the extract..

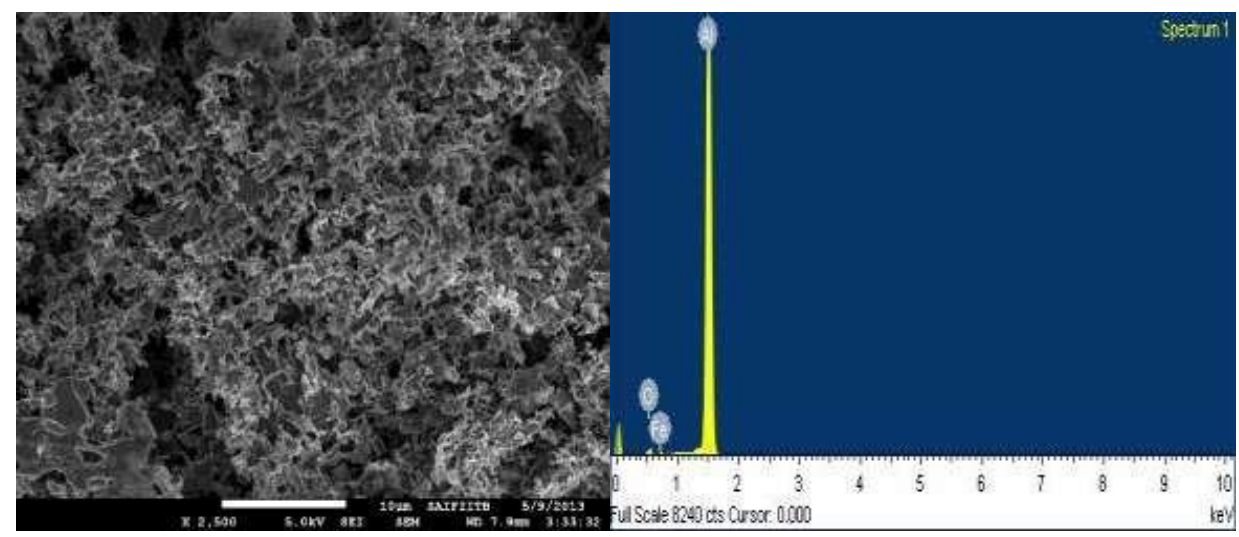

$\mathbf{a}$

b

Plate 1.0A (a) SEM IMAGE of Aluminium as received (b) EDX SPECTRUM of Aluminium as received

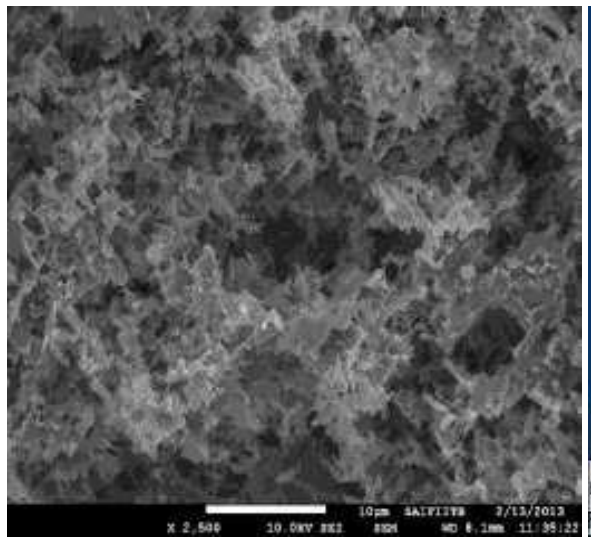

a

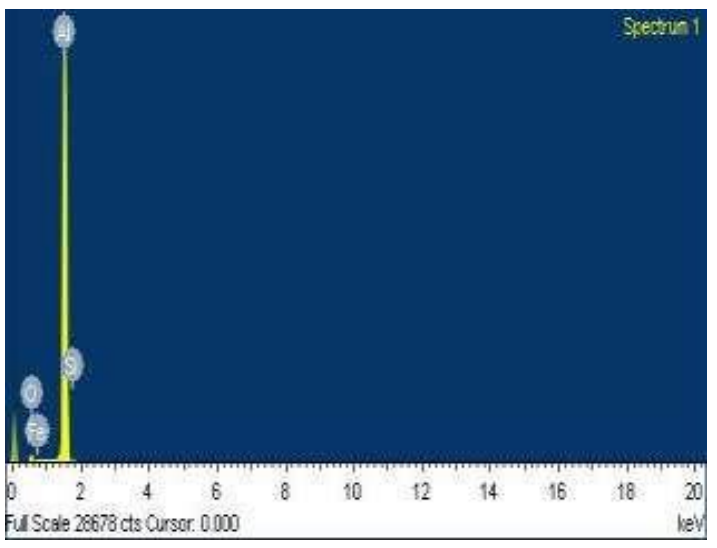

$\mathbf{b}$

Plate 2.0A(a) SEM IMAGE of Corroded Aluminium in 1.5 M HCl(Control),

(b) EDX Spectrum of Corroded Aluminium in $1.5 \mathrm{M} \mathrm{HCl}(\mathrm{Control})$ 


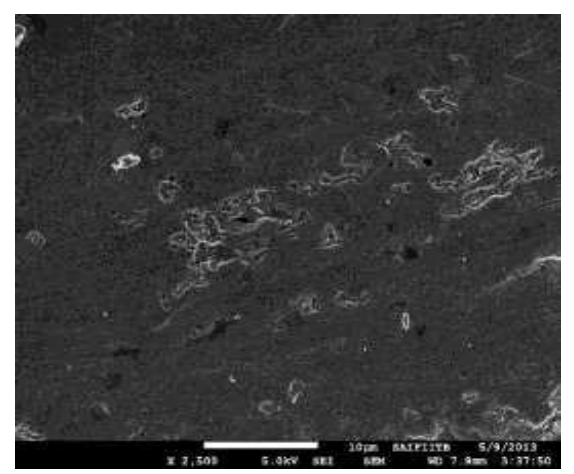

a

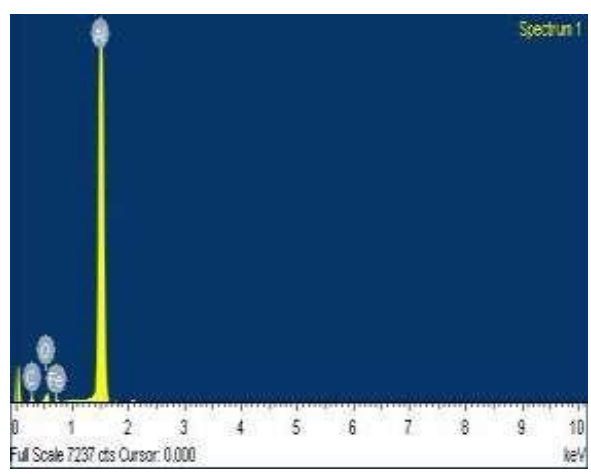

b

Plate 3.0A (a) SEM IMAGE of Aluminium in Telfaira occidentalis extract (b) EDX spectrum of Aluminium in Telfaira occidentalis extract

\section{Conclusions}

Methanolic extract of leaf of Telfaira occidentalis in $1.5 \mathrm{M} \mathrm{HCl}$ was investigated as green corrosion inhibitor for aluminium using the gasometric technique at $28^{\circ} \mathrm{C}$. There was about fifteen minute's induction period before the susceptibility of the aluminium sample to corrosion in the $\mathrm{HCl}$ media. This initial resistance to corrosion is due to strongly adhered oxide film on the aluminium surface. Removal of the oxide film by aggressive chloride ion in the medium took fifteen minutes before the aluminium surface is accessible for adsorption by the secondary metabolites in the extract.

The protected aluminium surface by the extract against acid attack was observed in the SEM analysis. The deduced long Half life of $\mathrm{t}_{1 / 2}=0.696546601 \times 10^{9}$ minutes depicts high retardation in corrosion reaction. The phytochemicals in the extract displayed high corrosion inhibition efficiency and the inhibition mechanism is explained by Langmuir adsorption isotherm having $\Delta \mathrm{G}\left(-13,319.00 \mathrm{Jmol}^{-1}\right.$.) which is an indication of spontaneous physical adsorption. This investigation proofed that TO be effective corrosion inhibitor by reducing the volume of hydrogen gas discharged from aluminium as well as slow down of the corrosion rate in the presence of acid environment.

\section{Acknowledgement:}

1) Covenant University, Ota for providing equipments for this work.

2) Dr S.A. Adeosun of Materials and Metallurgy Department, University of Lagos for useful advice

\section{References}

[1].Adeyeye E.I. ,. Omolayo F.O., Agric. Biol. J. N. Am., 2011, 2(3), 499-511.

[2].Agrawal Y.K., Talati J.D.M., Shah M.D., Desai M.N., Shah N.K., Corrosion Science, 2004, 46b, 633 - 651

[3].Ajayi, O. O., Omotosho, O. A., Ajanaku, K. O. and Olawore, B. O. 2011. Degradation of aluminium alloy in 2.0M $\mathrm{HCl}$ in the presence of Chromolaena Odorata, J Eng. Applied Sci 6(1), $10-17$

[4].Atkins, D. W. 1994. Physical chemistry, Oxford University Press, Oxford, $5^{\text {th }}$ Edition: 992.

[5].Burkill, H. M. 1985a. The useful plants of west tropical Africa. Royal Botanic Garden.Kew. Vol. 1: 603 - 604.

[6].Burkill H.M., The Useful Plants of West Tropical Africa, Royal Botanic Garden, Kew, 1985, 1, 52-53.

[7].Chengaiah B, Mallikarjuna Rao K, . Mahesh Kumar K, Alagusundaram M, Madhusudhana C, International Journal of PharmTech Research, 2(1), 144-154.

[8].Ebenso E.E., Obot I.B., Murulana I.C., Quinoline and its Derivates as effective Corrosion Inhibitors for Mild steel in Acidic Medium, International Journal of Electrochemical Science, 2010, 5, 1574 - 1586.

[9].Ehteram N.. and Al-Moubararaki, A. H. 2008b. Corrosion behaviour of Mild steel in hydrochloric acid solutions. Int. J Electrochem Sci. 3: 807.

[10]. Falcão L.. Eduarda M, Araújo M, Journal of Cultural Heritage, 2011, 12(2), 149-156. J. Buchweishaija, Tanz. J. Sci., 2009, 35, 77-92.

[11]. Gohari A.R., Saeidnia S, Mahmoodabadi M.K., Pharmacogn Rev., 2013, 7(13), 61-66.

[12]. James O.O., Ajanaku K.O, . Ogunniran K. O, Ajani O.O., SiyanbolaT.O. and John M.O. Trends in Applied Sciences Research, 2011, Academic Journal Inc.

[13]. James A.O., NOforka N.C.,Abiola K.O., Corrosion Inhibition of Mild Steel by Pyridoxal Hydrchloride and Pyridoxol Hydrochloride in 2M Hydrochloric Acid Journal Chemical Society, 2005, 203-205.

[14]. Lebrini, M., Bentiss, F., Vezin, H. and Lagrenee, M. 2006. Corrosion Science. $48: 1279$

[15]. Madukwe E.U, Nwabunze A.M., Onyibalu C.L., International Journal of Basic and Applied Sciences, 2013, 2(3), 251-257.

[16]. Nyananyo, B. L. 2006a. Plants from the Niger Delta, Onyoma Research Publications, :204.

[17]. Oboh G., J Med Food, 2005, 8(4), 560-563.

[18]. Rogerio A. P. , Sá-Nunes A, . Faccioli L. H, The activity of medicinal plants and secondary metabolites on eosinophilic inflammation, Pharmacol Res., 2010, 62(4), 298-307

[19]. Saxena M, Saxena J, Nema R, Singh D, Gupta A, Journal of Pharmacognosy and Phytochemistry, 2013, 1(6), 168182. 
[20]. Shetty, D. S., Shetty, P. and Nayak. H. V. S. 2006. Inhibition of Mildsteel Corrosion in acidic medium by N-(2thiophenyl)-N-phenyl thiourea. J. Chidean Chem. Soc., 51,2: 849 - 853

[21]. Safia Janju, Maliha Shahid and Fakhir-i-Abass 2013. Phytochemical analysis and in vitro antibacterial activity of root peel extract of Raphanus sativus

[22]. Tan K.W., Kassim M.J., Corrosion Science, 2011, 53, 569-574. Abdul-Ahad P.G. and Al-Madfai S.H.F., Elucidation of Corrosion Inhibition Mechanism by Means of Calculated Electronic Indexes, Corrosion, 1989, 45(12), 978-980

[23]. Umoren, S. A. Obot, I. B. Ebenso, E. E. Obi-Egbedi, N.O. 2008. Portugaliae Electrochima Acta 26:199

[24]. Vaishnay P, Demain A.L., Unexpected applications of secondary metabolites, Biotechnol Adv., 2011, 29(2), 223 239.

[25]. Vasudevan, T. and Mathur, P. B. 1982. Reactions Rate studies for the corrosion of metals in acid-I Iron in mineral acids Corrosion. NACE. 38, 3: $171-178$.

[26]. Yang, L., Zhang, H., Tan, T., and Rahman, A. U. 2009. Journal of Chemical Technology and Biotechnology, 84: $611-617$. 